Copyright (C) 2018 by Academic Publishing House Researcher

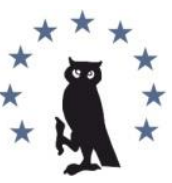

Published in the Russian Federation

European Researcher. Series A

Has been issued since 2010.

ISSN 2219-8229

E-ISSN 2224-0136

2018, 9(2): 176-184

DOI: $10.13187 /$ er.2018.2.176

www.erjournal.ru

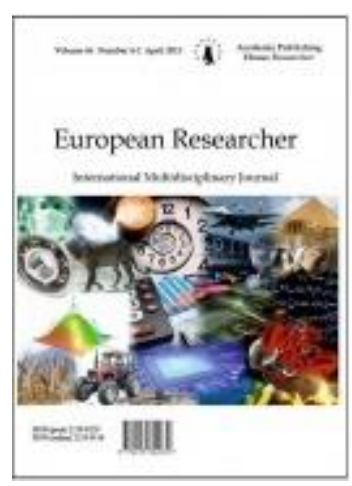

\title{
The Evolution of Approaches of Getting Higher Education: Distance Learning
}

Evgeniya V. Vidishcheva a , *

a Sochi state university, Russian Federation

\begin{abstract}
Science and technological progress and sustainable development of information technologies, cause the improvement of all spheres of modern person activity. The traditional education system is also passing through major changes. Advanced technologies in education provide universal availability of world information resources, create new opportunities, in particular, in the system of distance education - one of the most perspective systems for training specialists. The article presents the results of the study of the formation process of the distance education concept, identifies the main methods of distance transmission of knowledge and skills, and identifies key risk factors and prospects for further development.
\end{abstract}

Keywords: distant learning, e-learning, traditional education system.

\section{1. Введение}

Глобализация и информатизация - ключевые тенденции современного общества. Проникая практически во все сферы человеческой деятельности, информационные технологии выступают акселератором роста. Современная система образования является результатом достаточно продолжительного развития, однако далеко не все IT-достижения в данной сфере активно реализуются на практике. Актуальность исследования подходов к образовательному процессу обусловлена ростом потребности в создании и внедрении новой формы обучения, отвечающей стандартам и требованиям современного общества. Дистанционное обучение - совокупность информационно-технических разработок, позволяющая получать и передавать знания вне зависимости от места нахождения. Внедрение подобной системы в долгосрочной перспективе может привести к повышению грамотности и социальному уравниванию общества.

\section{2. Результаты исследования}

Образование - ключевой элемент долгосрочного и устойчивого развития, как отдельного государства, так и всего мира в целом. Именно от качества и эффективности функционирующей системы образования зависит дальнейшее процветание страны. Многие ученые посвятили свои работы исследованию процесса становления и развития образования. Несколько столетий назад возможность получения образования была обусловлена рядом социальных, материальных и территориальных факторов. Образование являлось недоступным для большинства людей. Широко известен пример Михаила Ломоносова, которому пришлось преодолеть более одной тысячи километров, чтобы

\footnotetext{
* Корреспондирующий автор

Адреса электронной почты: evgenia-vv@mail.ru (Е.В. Видищева)
} 
поступить в академию. Сегодня образование становится доступнее, во многом благодаря активному внедрению информационных технологий в процесс обучения. Однако в специализированной литературе встречаются различные мнения о соотношении преимуществ и недостатков данных изменений.

Сущность традиционного подхода к образовательному процессу отражена в работах многих ученых. Зборовский Г.Е. характеризует образование как формальный механизм получения документа об успешном прохождении образовательной программы, при это автор также подчеркивает роль образовательного процесса как особого социального института, в рамках которого происходит социализация обучаемого (Зборовский, 1994). Семенова Л.А. подчеркивает роль института образования как механизма контроля учащихся (Семенова, 2011). Представленные характеристики определяют суть образовательного процесса в его традиционном понимании. И стоит отметить, что данной точки зрения придерживается большинство специалистов. Из представленного выше следует, что в основу традиционной концепции образования заложены механизмы социального воспитания и контроля над учащимися. В этом и состоит основное отличие современных форм образовательного процесса. В частности, если рассматривать дистанционное обучение, в основе которого, по мнению Калининой А.И., лежит способность к самообучению и самодисциплине (Калинина, 2014). Другими словами, дистанционное обучение требует определенной подготовки: знание технической базы, наличие навыков владения компьютером, а также способность к самостоятельной работе. Глова В.И. ключевым отличием дистанционного образования от традиционного называет замену активного компонента в системе «знания-ученик»: вместо движения ученика к знаниям происходит движение знаний к учащимся (Глова, 2000). В литературе также встречается термин еlearning, означающий процесс обучения посредством сетевой среды. Российские ученые рассматривают e-learning как синоним дистанционного обучения, так как в современном мире дистанционное образование без использования электронных средств передачи данных не представляется возможным. Недостатки данного вида обучения, описанные в литературе, основаны именно на наличии подобных характеристик, отличающих новый вид обучения от принятой и проверенной годами системы. Среди слабых сторон чаще всего выделяют отсутствие должного контроля (большую роль играет личная заинтересованность и мотивация учащегося), недостоверность аутентификации пользователя (не все системы дистанционной проверки знаний оборудованы комплексами видео-аутентификации аттестуемого), а также недостаток личного общения и практики. Но прогресс не стоит на месте и дистанционное обучение в современном быстроизменяющемся мире находится в процессе постоянного развития. Ежегодно появляются новые технологические решения, позволяющие обогащать и совершенствовать действующую систему. Как менялся с годами инструментарий дистанционного образования представлено на рисунке 1.

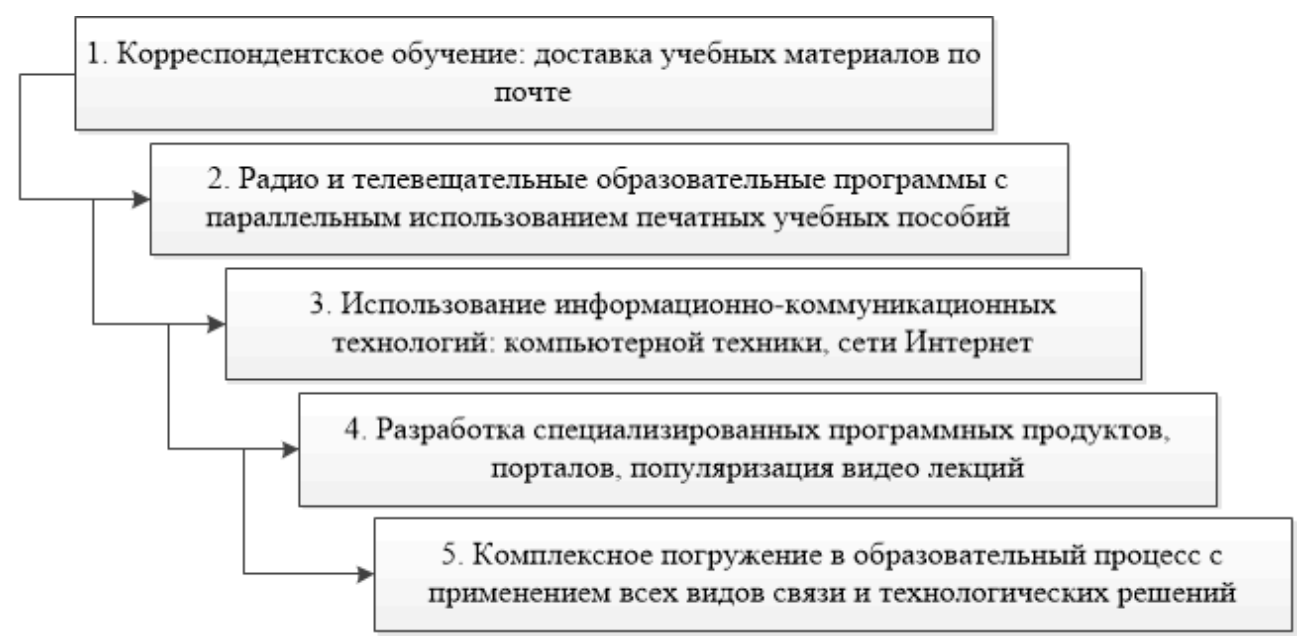

Рис. 1. Этапы развития дистанционного обучения 
Как видно из рисунка 1 научно-технические достижения активно реализуются в сфере образования. Началом развития дистанционного обучения в современном понимании, то есть с использованием средств электронного обмена данными, можно считать вторую половину 80-х годов 20 века. Наиболее динамичное развитие данного рынка началось с создания и распространения сети Интернет, повлекшее за собой рост количества интернетпользователей, влияние социальных сетей и развитие прочих электронных систем. Одной из первых электронных технологий, использованных в сфере дистанционного обучения, является электронная почта. Первый бесплатный почтовый сервис RocketMail был запущен в 1996 году, после чего возможность передачи данных на удаленный компьютер стали использовать в различных отраслях и сферах, в том числе и в образовании. По данным RadicatiGroup, количество активных учетных записей электронной почты к концу 2017 года составляет 4,9 миллиарда (Email Statistics Report, 2016-2020). Облик интернета за 25 лет сильно изменился, появились новые возможности для общения и обмена данными, а электронная почта по-прежнему остается одним из основных каналов связи, количество отправленных сообщений и учетных записей ежегодно возрастает. В начале 21 века существовала гипотеза, что с развитием сети Интернет, появлением социальных сетей и прочих современных средств связи, электронная почта потеряет свою актуальность. Однако, несмотря на изобилие технологий и новшеств, электронная почта пользуется популярностью.

В 1998 году произошло еще одно знаковое событие в становлении современного дистанционного обучения. Выпускники Стенфордского университета Сергей Брин и Ларри Пейдж создали поисковую систему Google, благодаря которой можно за считанные секунды получить информацию о любой сфере деятельности, науки или жизни. Сегодня система обрабатывает более 200 миллионов запросов на 80 языках мира ежегодно.

Следующим важным этапом в формировании системы электронного обучения можно считать 2004 - 2005 годы, отмеченные активным развитием технологий, позволяющих осуществлять обмен данными, денежными средствами и документацией из любой точки мира с помощью карманных гаджетов.В образовательных программах высших учебных заведений мобильные устройства не входят в перечень ключевых инструментов передачи знаний. Но при этом портативные решения активно используются в качестве источника информации при повышении квалификации, профессиональной переподготовке и общем расширении кругозора. Существует множество программных продуктов образовательного характера, таких как приложения для изучения иностранных языков (Duolingo, Lingualeo), для подготовки к единым государственным или вступительным экзаменам, в том числе и к экзамену на знание правил дорожного движения.

Основными средствами дистанционного обучения являются специализированные системы дистанционного образования, дистанционные курсы и прочие технологии (Skype, электронная почта, электронные библиотеки). Совокупность технологий, используемых в процессе дистанционной передачи знаний, можно разделить на информационные и коммуникационные. В первую группу входят локальные источники информации, такие как мультимедийные курсы, электронные книги, аудио- и видеокассеты, позволяющие в свободном режиме осваивать материал без непосредственного контакта с преподавателем. К числу коммуникационных технологий относят любые взаимодействия образовательного характера, осуществляемые через сетевые источники связи (чаты, рассылки, телеконференции и прочее). Полный перечень современных технологических решений в дистанционном образовании представлен на рисунке 2. 


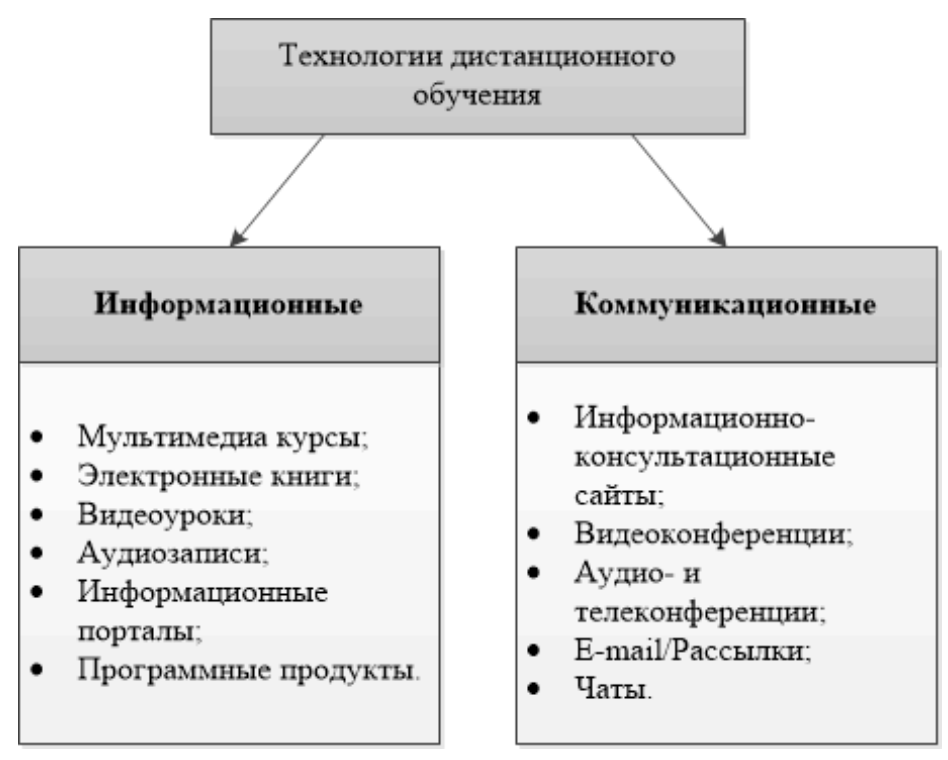

Рис. 2. Современные технологии дистанционного обучения

В основе всех представленных технологий лежит глобальная сеть Интернет. Современные статистические исследования интернет-аудитории показывают неуклонное увеличение числа пользователей сети. Количество пользователей сети в январе 2018 года превысило 4 млрд. человек, что на 7 \% больше по сравнению с аналогичным периодом прошлого года (Digital in 2018). Интернет проникает в различные сферы жизни и является характерной чертой постиндустриального общества. Будущее развитие дистанционного образования во многом обусловлено равномерностью проникновения сети Интернет в мире.

Согласно «Концепции создания и развития системы дистанционного образования в России», дистанционное образование представляет собой комплекс образовательных услуг, предоставляемых широким слоям населения в стране и за ее пределамипосредством специализированной информационно-образовательной среды, основанной на средствах электронного обмена учебной информацией (Концепции создания...). По своей сути дистанционное образование является инновационным инструментом достижения основной цели учащихся - получение знаний. Инновационные технологии в учебных заведениях являются условием повышения качества образования, и, следовательно, роста конкурентоспособности заведения на рынке образовательных услуг. Сегодня многие университеты уже активно используют онлайн площадки, как для дистанционного обучения, так и в качестве дополнения традиционной формы получения знаний. Как выглядит процесс дистанционного образования и чем отличатся от традиционной формы представлено на рисунке 3.
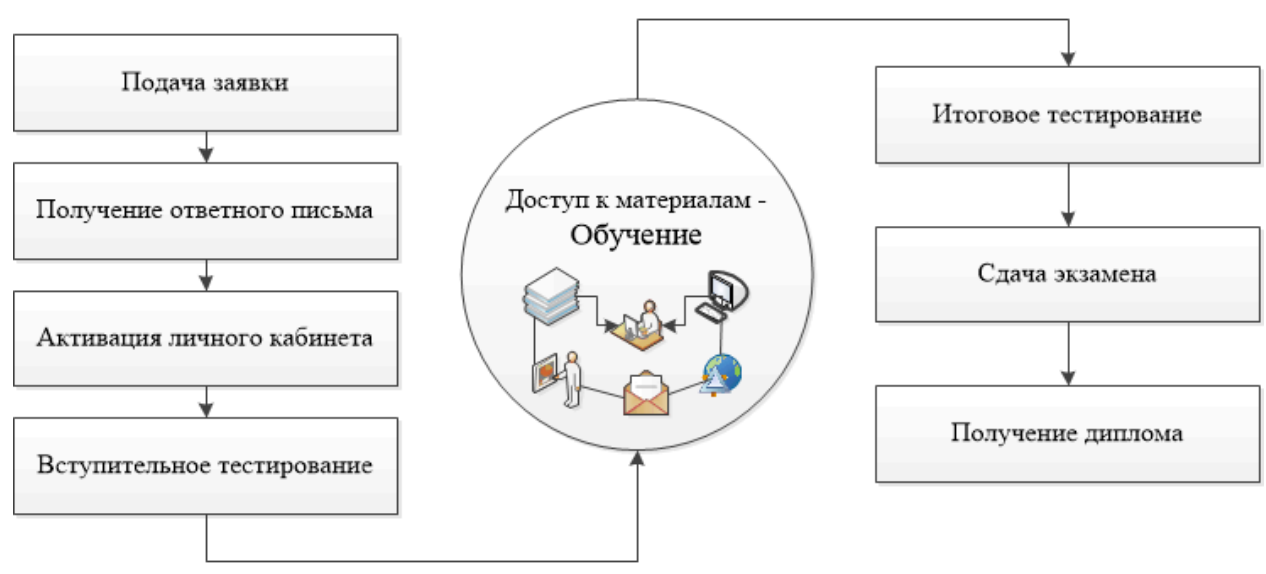

Рис. 3. Процесс дистанционного обучения 
Ключевые отличия современного способа получения образования заключаются в форме вступительного и основного этапов. Подача документов, вступительные экзамены и сам образовательный процесс в дистанционной форме осуществляются посредством электронного обмена данными. Технические достижения, используемые при дистанционной подготовке, также являются источником разнообразия средств и методик учебного процесса.

Привлечение инструментов дистанционного обучения в традиционную систему образования приводит к формированию новой формы учебного процесса - смешанной. Основные инструменты традиционного и дистанционного обучения представлены на рисунке 4 .

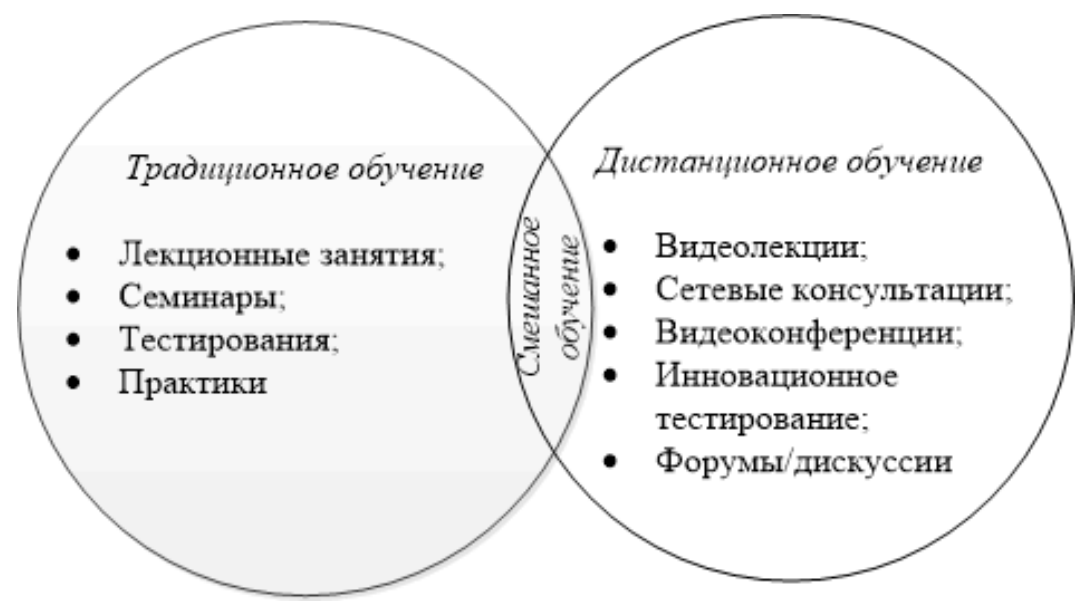

Рис. 4. Инструментарий традиционного и дистанционного обучения

Сегодня сложно представить образовательный процесс без использования видеоматериалов, баз данных удаленного доступа и прочих сетевых методов передачи знаний. Таким образом, на современном этапе развития дистанционное образование не только активно развивается как обособленное направление, но и дополняет традиционную систему.

Обмен лекционными материалами, онлайн консультации и прочие электронные взаимодействия обучаемого с преподавателем не обеспечивают полноценность образовательного процесса. Для разработки, контроля и распространения учебных материалов с обеспечением совместного единовременного доступа сегодня используются системы LMS (LearningManagementSystem). Они лежат в основе дистанционного обучения и представляют собой комплексы для управления учебным процессом. Посредством данной системы возможна организация и контроль выполнения электронных образовательных программ и курсов, а также общее администрирование, в том числе и традиционной формы обучения (Смирнова, 2014). Существуют как общедоступные (Moodle, ATutor, Claroline), так и платные (eLearningServer, MicrosoftLearningGateway) площадки. Подобные разработки используются высшими учебными заведениями для поддержкидистанционного образовательного процесса, а также коммерческими организациями и компаниями с целью повышения квалификации персонала. Одной из наиболее популярных систем сегодня является Moodle.Многие высшие учебные заведения используют данную платформу. Среди крупнейших пользователей Краснодарского края КубГУ, КубГТУ, МГУТУ им. К.Г. Разумовского. Обширный функционал системного комплекса позволяет создавать различные программы и курсы, уникальные по своему содержанию. Доступ к системе возможен из любого браузера и программного обеспечения (Windows, OpenOffice). Функциональные возможности подобных систем включают:

1. Разработка и произвольная компоновка обучающей программы/курса;

2. Постоянный доступ преподавателей и студентов к материалу;

3. Контроль выполнения студентом требуемого минимума;

4. Площадка для взаимодействия участников образовательного процесса; 
5. Контроль/проверка полученных знаний.

Важнейшим элементом современных систем дистанционного обучения является простота и наглядность навигационной панели и интерфейса. Пример стартовой страницы студента представлен на рисунке 5 .

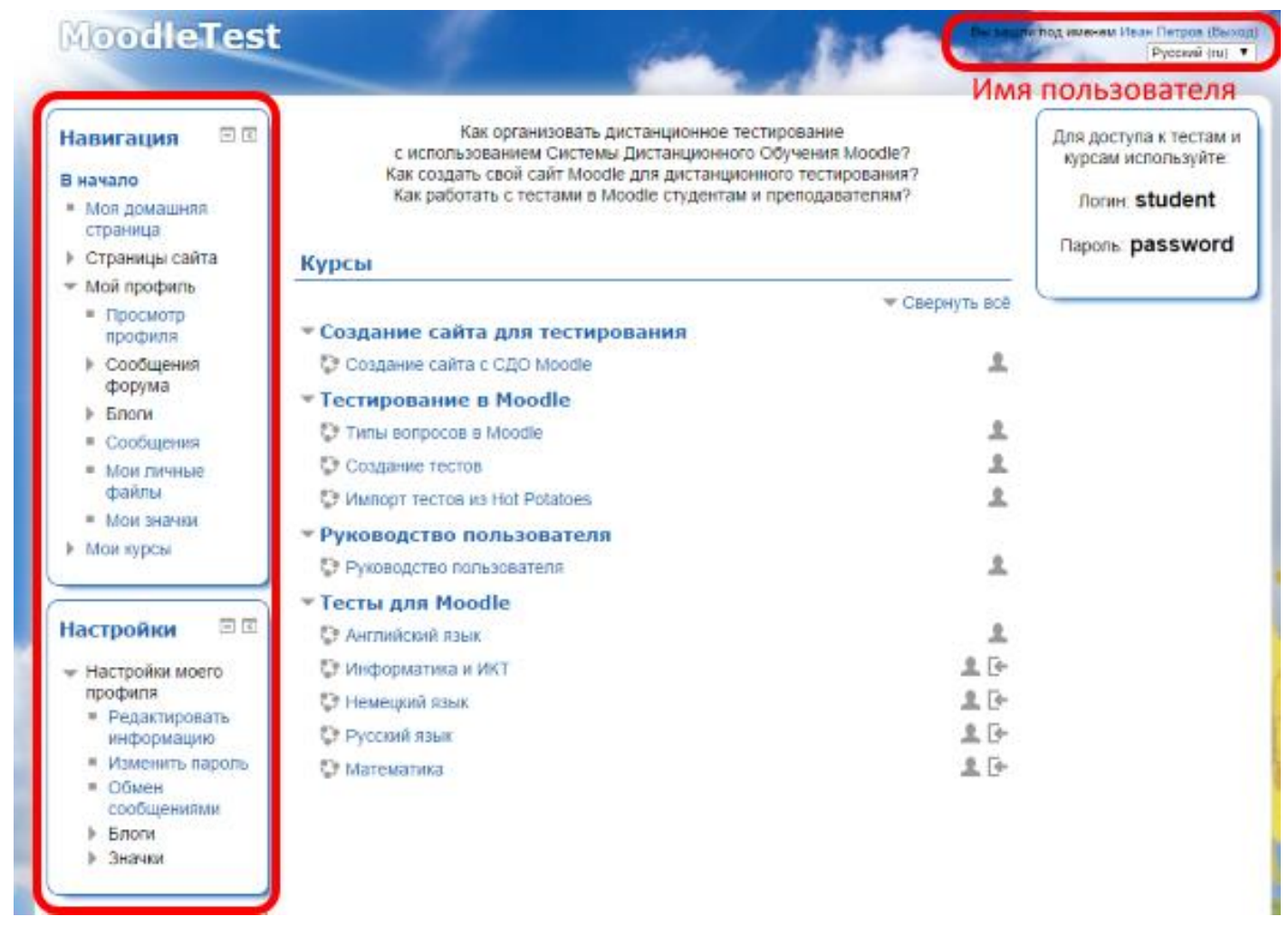

Рис.5. Интерфейс пользователя (студента) системы Moodle (Moodle-учебник для начинающих)

При помощи системы обучаемый получает доступ ко всем материалам, может самостоятельно выбрать курс, если такая возможность предусмотрена автором, а также оформлять и структурировать интерфейс по своему усмотрению.

Внедрение научно-технических достижений в образовательный процесс приводит к повышению доступности и эффективности образования, позволяя охватывать большие аудитории с меньшими материальными и трудовыми затратами. Как и у любой системы, у дистанционного образования, безусловно, есть свои недостатки. В таблице 1 представлено соотношение положительных и отрицательных аспектов дистанционного обучения.

Таблица 1. Преимущества и недостатки дистанционной системы обучения

\begin{tabular}{|l|l|}
\hline Преимущества & Недостатки \\
\hline Индивидуальный подход; & Отсутствие унифицированного подхода к \\
Гибкий график обучения; & стандартизации и оценке качества \\
Доступность обучения и учебных & дистанционного образования; \\
материалов; & Сложность идентификации личности \\
Оперативное взаимодействие участников & обучаемого; \\
обучения; & Недостаток живого общения; \\
Высокая технологичность & Необходимость высокого уровня \\
образовательного процесса; & самоорганизации потенциальных учеников; \\
Социально-экономическая доступность & Низкий уровень доверия к подобным \\
образования & системам в обществе \\
\hline
\end{tabular}


На основе перечисленных характеристик можно вывести ключевые факторы развития дистанционного образования. Среди стимулирующих факторов стоит выделить:

- высокие темпы научно-технического прогресса;

- рост спроса на высококвалифицированную рабочую силу;

- заинтересованность государства в развитии системы образования в стране;

- повышение потребительского интереса и спроса наданный вид услуг;

- рост проникновения сети Интернет;

- крупные инвестиционные потоки в IT сферу.

К наиболее весомым сдерживающим факторам отнесем:

- неравномерность компьютеризации общества и проникновения сети Интернет (в России на начало 2018 года доступ к глобальной сети имеют около 73 \% населения) (Digital in 2018);

- недоверие людей к электронным системам, в том числе к дистанционной системе проверки знаний;

- неразвитость ИТ инфраструктуры и законодательства;

- периодические перебои с энергоснабжением;

- высокий уровень мошенничества;

- риски в сфере безопасности;

• низкий уровень контроля дисциплины учащихся.

Устойчивая информатизация общества приводит к устойчивому переводу традиционных видов деятельности в сеть. В современном мире практически любой товар или услугу можно заказать через глобальную сеть, государство проводит активную компьютеризацию бюджетных сфер, таких как медицина, образование и оказание консультационно-правовых услуг населению. С момента зарождения и по сей день система дистанционного обучения находится в постоянном развитии, появляются новые формы, инструменты и методы передачи знаний, привлекаются новейшие научно-технические разработки. Перспективность дальнейшего развития системы дистанционной передачи знаний связана с интенсивным развитием интернет технологий и методик обучения.

\section{3. Заключение}

Дистанционное образование представляет собой уникальную возможность для многих людей получить образование, повысить квалификацию, пройти переподготовку, найти или сменить работу без отрыва от основной деятельности. Ключевым достоинством дистанционной системы для российских абитуриентов является возможность получения диплома международного образца без дополнительных затрат на переезд и проживание за границей.

Несмотря на относительно продолжительную историю становления и развития, дистанционная система обучения имеет огромный потенциал для дальнейшего роста. Помимо разработки новых и совершенствования уже существующих технологий, важнейшим направлением будущего развития данной сферы должно стать донесение конечного продукта - услуг дистанционного обучения - до потребителя, путем повышения уровня доверия населения к системе, а такжеулучшениекачества образовательного продукта, в том числе за счет совершенствования процедуры итоговой проверки знаний.

\section{Литература}

GfK... - GfK: за год количество интернет-пользователей в России выросло на 3 млн. URL: $\quad$ http://www.telesputnik.ru/materials/video-v-internete/news/gfk-za-god-kolichestvointernet-polzovateley-v-rossii-vyroslo-na-3-mln/ (дата обращения: 20.04.2018).

Moodle-учебник для начинающих - Moodle-учебник для начинающих. URL: https://rumoodler.com/ (дата обращения: 23.04.2018).

Глова, 2000 - Глова В.И. Дистанционное образование - новые формы и технологии образования // ВЕСТНИК КГТУ им. А.Н. ТУПОЛЕВА, № 1. 2000, С. 48-51.

Зборовский, 1994 - Зборовский Г.Е. Социология образования: в 2ч. Ч. 2 . Социология профессионального образования. Екатеринбург: Изд-во Урал.гос. проф.-пед. Ун-та, 1994, $228 \mathrm{c}$. 
Калинина, 2014 - Калинина А.И. Дистанционное обучение как часть системы непрерывного образования и роль самообразования в дистанционном обучении // Вестник Московского ун-та сер.20 Педагогическое образование. №1. 2014.

Концепции создания... - Концепции создания и развития системы дистанционного образования в России. URL: http://pandia.ru/text/78/302/22561.php (дата обращения: 19.04.2018).

Семенова, 2011 - Семенова Л.А. Кадровый потенциал постсоветской России: потери, обретения, проблемы. Социологический анализ, Saarbruken: LambertAcademicPublishing, 2011, 98 c.

Смирнова, 2014 - Смирнова Н.А. Системы управления обучением в дистанционном образовании / Сборник конференции НИЦ Социосфера. Vedeckovydavatelskecentrum Sociosfera-CZs.r.o. (Прага). №25. 2014, C. 129-131.

Digital in 2018 - Digital in 2018: World's internet users pass the 4 billion mark. URL: https://wearesocial.com/blog/2018/o1/global-digital-report-2018 (дата обращения: 19.04.2018)

Email Statistics Report, 2016-2020 - Email Statistics Report, 2016-2020 - The Radicati Group, Inc. URL: www.radicati.com (дата обращения: 20.04.2018).

\section{References}

GfK... - GfK: za god kolichestvo internet-pol'zovatelei v Rossii vyroslo na $3 \mathrm{mln}$. [GfK: for the year the number of Internet users in Russia increased by 3 million]. URL: http://www.telesputnik.ru/materials/video-v-internete/news/gfk-za-god-kolichestvo-internetpolzovateley-v-rossii-vyroslo-na-3-mln/ (data obrashcheniya: 20.04.2018)

Moodle-uchebnik dlya nachinayushchikh - Moodle-uchebnik dlya nachinayushchikh [Moodle-textbook for beginners]. URL: https://rumoodler.com/ (data obrashcheniya: 23.04.2018).

Glova, 2000 - Glova V.I. (2000). Distantsionnoe obrazovanie - novye formy i tekhnologii obrazovaniya [Distance Education - New Forms and Technologies of Education]. VESTNIK KGTU im. A.N. TUPOLEVA, № 1. pp. 48-51.

Zborovskii, 1994 - Zborovskii G.E. (1994). Sotsiologiya obrazovaniya [Sociology of Education]: v 2ch. Ch. 2 . Sotsiologiya professional'nogo obrazovaniya. Ekaterinburg: Izd-vo Ural.gos. prof.-ped. Un-ta, 228 p.

Kalinina, 2014 - Kalinina A.I. (2014). Distantsionnoe obuchenie kak chast' sistemy nepreryvnogo obrazovaniya i rol' samoobrazovaniya $\mathrm{v}$ distantsionnom obuchenii [Distance learning as part of the system of continuous education and the role of self-education in distance education]. Vestnik Moskovskogo un-ta ser.2o Pedagogicheskoe obrazovanie. №1.

Kontseptsii sozdaniya... - Kontseptsii sozdaniya i razvitiya sistemy distantsionnogo obrazovaniya $\mathrm{v}$ Rossii [Concepts of creation and development of the system of distance education in Russia]. URL: http://pandia.ru/text/78/302/22561.php (data obrashcheniya: 19.04.2018).

Semenova, 2011 - Semenova L.A. (2011). Kadrovyi potentsial postsovetskoi Rossii: poteri, obreteniya, problem [Personnel potential of post-Soviet Russia: losses, acquisitions, problems]. Sotsiologicheskii analiz, Saarbruken: LambertAcademicPublishing, 98 p.

Smirnova, 2014 - Smirnova N.A. (2014). Sistemy upravleniya obucheniem v distantsionnom obrazovanii [Learning management systems in distance education]. Sbornik konferentsii NITs Sotsiosfera. VedeckovydavatelskecentrumSociosfera-CZs.r.o. (Praga). №25. pp. 129-131.

Digital in 2018 - Digital in 2018: World's internet users pass the 4 billion mark. URL: https://wearesocial.com/blog/2018/01/global-digital-report-2018 (data obrashcheniya: 19.04.2018)

Email Statistics Report, 2016-2020 - Email Statistics Report, 2016-2020 - The Radicati Group, Inc. URL: www.radicati.com (data obrashcheniya: 20.04.2018) 


\section{Эволюция подходов к получению высшего образования: дистанционное обучение}

\section{Евгения Владимировна Видищева ${ }^{\text {a, * }}$}

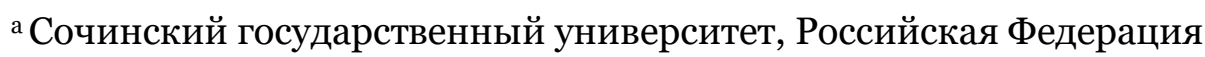

Аннотация. Научно-технический прогресс и устойчивое совершенствование информационных технологий, обуславливают развитие всех сфер деятельности современного человека. Традиционная система образования также претерпевает серьезные изменения. Передовые технологии в образовании обеспечивают общедоступность мировых информационных ресурсов, создают новые возможности в образовательной системе, в частности, в системе дистанционного образования - одной из перспективнейших систем подготовки специалистов. В статье представлены результаты исследования процессаформирования концепции дистанционного образования, выделены основные методы дистанционной передачи знаний и умений, определены ключевые факторы риска и перспективы дальнейшего развития.

Ключевые слова: дистанционное обучение, электронное обучение, традиционная система образования.

\footnotetext{
${ }^{*}$ Корреспондирующий автор

Адреса электронной почты: evgenia-vv@mail.ru (Е.В. Видищева)
} 